\title{
An application of measures of noncompactness in the investigation of boundedness of solutions of second-order neutral difference equations
}

Ewa Schmeidel*

"Correspondence:

eschmeidel@math.uwb.edu.pl Institute of Mathematics, University of Białystok, Białystok, Poland

\begin{abstract}
The purpose of this paper is to investigate a nonlinear second-order neutral difference equation of the form

$$
\Delta\left(r_{n} \Delta\left(x_{n}+p_{n} x_{n-k}\right)\right)+a_{n} f\left(x_{n}\right)=0,
$$

where $x: \mathbb{N}_{0} \rightarrow \mathbb{R}, a: \mathbb{N}_{0} \rightarrow \mathbb{R}, p, r: \mathbb{N}_{0} \rightarrow \mathbb{R} \backslash\{0\}, f: \mathbb{R} \rightarrow \mathbb{R}$ is a continuous function, and $k$ is a given positive integer. Sufficient conditions for the existence of a bounded solution of this equation are obtained. Also, stability and asymptotic stability of this equation are studied. Additionally, the Emden-Fowler difference equation is considered as a special case of the above equation. The obtained results are illustrated by examples.

MSC: 39A10; 39A22; 39A30
\end{abstract}

Keywords: difference equation; measures of noncompactness; Darbo's fixed point theorem; boundedness; stability; Emden-Fowler equation

\section{Introduction}

In presented paper we study a nonlinear second-order difference equation of the form

$$
\Delta\left(r_{n} \Delta\left(x_{n}+p_{n} x_{n-k}\right)\right)+a_{n} f\left(x_{n}\right)=0,
$$

where $x: \mathbb{N}_{0} \rightarrow \mathbb{R}, a: \mathbb{N}_{0} \rightarrow \mathbb{R}, p, r: \mathbb{N}_{0} \rightarrow \mathbb{R} \backslash\{0\}$, and $f: \mathbb{R} \rightarrow \mathbb{R}$ is a continuous function. Here $\mathbb{N}_{0}:=\{0,1,2, \ldots\}, \mathbb{N}_{k}:=\{k, k+1, k+2, \ldots\}$, where $k$ is a given positive integer and $\mathbb{R}$ is a set of all real numbers. By a solution of equation (1), we mean a sequence $x: \mathbb{N}_{0} \rightarrow \mathbb{R}$ which satisfies (1) for every $n \in \mathbb{N}_{0}$.

Putting $f(x)=x^{\gamma}$, where $\gamma<1$ is a quotient of two odd integers, $r_{n} \equiv 1$ and $p_{n} \equiv p \in$ $(0, \infty), p \neq 1$ in equation (1), we get an Emden-Fowler difference equation of the form

$$
\Delta^{2}\left(x_{n}+p x_{n-k}\right)+a_{n} x_{n}^{\gamma}=0 .
$$

In the last years many authors have been interested in studying the asymptotic behavior of solutions of difference equations, in particular, second-order difference equations (see,

\section{丵 Springer}

(c) 2013 Schmeidel; licensee Springer. This is an Open Access article distributed under the terms of the Creative Commons Attribution License (http://creativecommons.org/licenses/by/2.0), which permits unrestricted use, distribution, and reproduction in any medium, provided the original work is properly cited. 
for example, papers of Medina and Pinto [1], Migda [2], Migda and Migda [3], Migda et al. [4], Musielak and Popenda [5], Popenda and Werbowski [6], Schmeidel [7], Schmeidel and Zbạszyniak [8] and Thandapani et al. [9]).

Neutral difference equations were studied in many other papers by Grace and Lalli [10] and [11], Lalli and Zhang [12], Migda and Migda [13], Luo and Bainov [14], and Luo and $\mathrm{Yu}[15]$.

Some relevant results related to this topic can be found in papers by Baštinec et al. [16], Baštinec et al. [17], Berezansky et al. [18], Diblík and Hlavičková [19], and Diblík et al. [20].

For the reader's convenience, we note that the background for difference equations theory can be found, e.g., in the well-known monograph by Agarwal [21] as well as in those by Elaydi [22], Kocić and Ladas [23], or Kelley and Peterson [24].

The theory of measures of noncompactness can be found in the book of Akhmerov et al. [25] and in the book of Banaś and Goebel [26]. In our paper, we used axiomatically defined measures of noncompactness as presented in paper [27] by Banaś and Rzepka.

\section{Measures of noncompactness and Darbo's fixed point theorem}

Let $(E,\|\cdot\|)$ be an infinite-dimensional Banach space. If $X$ is a subset of $E$, then $\bar{X}$, $\operatorname{Conv} X$ denote the closure and the convex closure of $X$, respectively. Moreover, we denote by $\mathcal{M}_{E}$ the family of all nonempty and bounded subsets of $E$ and by $\mathcal{N}_{E}$ the subfamily consisting of all relatively compact sets.

Definition 1 A mapping $\mu: \mathcal{M}_{E} \rightarrow[0, \infty)$ is called a measure of noncompactness in $E$ if it satisfies the following conditions:

$1^{\circ} \operatorname{ker} \mu=\left\{X \in \mathcal{M}_{E}: \mu(X)=0\right\} \neq \emptyset$ and $\operatorname{ker} \mu \subset \mathcal{N}_{E}$,

$2^{\circ} X \subset Y \Rightarrow \mu(X) \leq \mu(Y)$

$3^{\circ} \mu(\bar{X})=\mu(X)=\mu(\operatorname{Conv} X)$,

$4^{\circ} \mu(\alpha X+(1-\alpha) Y) \leq \alpha \mu(X)+(1-\alpha) \mu(Y)$ for $0 \leq \alpha \leq 1$,

$5^{\circ}$ if $X_{n} \in \mathcal{M}_{E}, X_{n+1} \subset X_{n}, X_{n}=\bar{X}_{n}$ for $n=1,2,3, \ldots$ and $\lim _{n \rightarrow \infty} \mu\left(X_{n}\right)=0$, then $\bigcap_{n=1}^{\infty} X_{n} \neq \emptyset$.

The following Darbo's fixed point theorem given in [27] is used in the proof of the main result.

Theorem 1 Let $M$ be a nonempty, bounded, convex, and closed subset of the space $E$, and let $T: M \rightarrow M$ be a continuous operator such that $\mu(T(X)) \leq k \mu(X)$ for all nonempty subset $X$ of $M$, where $k \in[0,1)$ is a constant. Then $T$ has a fixed point in the subset $M$.

We consider the Banach space $l^{\infty}$ of all real bounded sequences $x: \mathbb{N}_{0} \rightarrow \mathbb{R}$ equipped with the standard supremum norm, i.e.,

$$
\|x\|=\sup _{n \in \mathbb{N}_{0}}\left|x_{n}\right| \quad \text { for } x \in l^{\infty} .
$$

Let $X$ be a nonempty, bounded subset of $l^{\infty}, X_{n}=\left\{x_{n}: x \in X\right\}$ (it means $X_{n}$ is a set of $n$th terms of any sequence belonging to $X$ ), and let

$$
\operatorname{diam} X_{n}=\sup \left\{\left|x_{n}-y_{n}\right|: x, y \in X\right\}
$$


We use the following measure of noncompactness in the space $l^{\infty}$ (see [26]):

$$
\mu(X)=\limsup _{n \rightarrow \infty} \operatorname{diam} X_{n} .
$$

\section{Main result}

In this section, sufficient conditions for the existence of a bounded solution of equation (1) are derived. Further, stable solutions of (1) are studied. We start with the following theorem.

\section{Theorem 2 Let}

$$
f: \mathbb{R} \rightarrow \mathbb{R} \text { be a continuous function, }
$$

and let there exist constants $L$ and $M$ such that for all $x \in \mathbb{R}$,

$$
|f(x)| \leq M|x|+L
$$

the sequence $p: \mathbb{N}_{0} \rightarrow \mathbb{R} \backslash\{0\}$ satisfies the following condition:

$$
-1<\liminf _{n \rightarrow \infty} p_{n} \leq \limsup _{n \rightarrow \infty} p_{n}<1
$$

sequences $a: \mathbb{N}_{0} \rightarrow \mathbb{R}, r: \mathbb{N}_{0} \rightarrow \mathbb{R} \backslash\{0\}$ are such that

$$
\sum_{n=0}^{\infty}\left|\frac{1}{r_{n}}\right| \sum_{i=n}^{\infty}\left|a_{i}\right|<\infty
$$

Then there exists a bounded solution $x: \mathbb{N}_{0} \rightarrow \mathbb{R}$ of equation (1).

Proof Condition (5) implies that there exist $n_{1} \in \mathbb{N}_{0}$ and a constant $P \in[0,1)$ such that

$$
\left|p_{n}\right| \leq P<1 \quad \text { for } n \geq n_{1} .
$$

The remainder of a series is the difference between the $n$th partial sum and the sum of a series. Let us denote by $\alpha_{n}$ the remainder of series $\sum_{n=0}^{\infty}\left|\frac{1}{r_{n}}\right| \sum_{i=n}^{\infty}\left|a_{i}\right|$ so that

$$
\alpha_{n}=\sum_{j=n}^{\infty}\left|\frac{1}{r_{j}}\right| \sum_{i=j}^{\infty}\left|a_{i}\right|
$$

From (6), the remainder $\alpha_{n}$ tends to zero. Therefore, we can denote

$$
\lim _{n \rightarrow \infty} \alpha_{n}=0 .
$$

Let us denote that $C$ is a given positive constant. Condition (6) implies that there exists a positive integer $n_{2}$ such that

$$
\alpha_{n} \leq C \frac{1-P}{2(C M+L)}
$$

for $n \geq n_{2}$. 
We define a set $B$ as follows:

$$
B:=\left\{\left(x_{n}\right)_{n=0}^{\infty}:\left|x_{n}\right| \leq C \text { for } n \in \mathbb{N}_{n_{3}}\right\},
$$

where $\mathbb{N}_{n_{3}}:=\left\{n_{3}, n_{3}+1, n_{3}+2, \ldots\right\}$ and $n_{3}=\max \left\{n_{1}, n_{2}\right\}$.

It is not difficult to prove that $B$ is a nonempty, bounded, convex, and closed subset $l^{\infty}$. Let us define a mapping $T: B \rightarrow l^{\infty}$ as follows:

$$
(T x)_{n}=-p_{n} x_{n-k}-\sum_{j=n}^{\infty} \frac{1}{r_{j}} \sum_{i=j}^{\infty} a_{i} f\left(x_{i}\right)
$$

for any $n \in \mathbb{N}_{n_{3}}$.

We will prove that the mapping $T$ has a fixed point in $B$.

Firstly, we show that $T(B) \subset B$. Indeed, if $x \in B$, then by (12), (7), (11), and (10), we have

$$
\begin{aligned}
\left|(T x)_{n}\right| & \leq\left|p_{n}\right|\left|x_{n-k}\right|+\sum_{j=n}^{\infty}\left|\frac{1}{r_{j}}\right| \sum_{i=j}^{\infty}\left|a_{i}\right|\left|f\left(x_{i}\right)\right| \\
& \leq P C+\sum_{j=n}^{\infty}\left|\frac{1}{r_{j}}\right| \sum_{i=j}^{\infty}\left|a_{i}\right|\left(M\left|x_{i}\right|+L\right) \\
& \leq C P+(M C+L) \sum_{j=n}^{\infty}\left|\frac{1}{r_{j}}\right| \sum_{i=j}^{\infty}\left|a_{i}\right| \\
& \leq C P+(C M+L) \alpha_{n}=C \frac{P+1}{2} \leq C \quad \text { for } n \in \mathbb{N}_{n_{3}} .
\end{aligned}
$$

Next, we prove that $T$ is continuous. Let $x^{(p)}$ be a sequence in $B$ such that $\left\|x^{(p)}-x\right\| \rightarrow 0$ as $p \rightarrow \infty$. Because of (3), we have $\left\|f\left(x^{(p)}\right)-f(x)\right\| \rightarrow 0$. Since $B$ is closed, $x \in B$. Now, utilizing (12), we get

$$
\left|\left(T x^{(p)}\right)_{n}-(T x)_{n}\right| \leq\left|p_{n}\right|\left|x_{n-k}^{(p)}-x_{n-k}\right|+\sum_{j=n}^{\infty}\left|\frac{1}{r_{j}}\right| \sum_{i=j}^{\infty}\left|a_{i}\right|\left|f\left(x_{i}^{(p)}\right)-f\left(x_{i}\right)\right| .
$$

Hence, by (7) and (8),

$$
\left|\left(T x^{(p)}\right)_{n}-(T x)_{n}\right| \leq P\left|x_{n-k}^{(p)}-x_{n-k}\right|+\alpha_{n} \sup _{i \geq n}\left|f\left(x_{i}^{(p)}\right)-f\left(x_{i}\right)\right|, \quad n \in \mathbb{N}_{n_{3}} .
$$

Therefore, by (10),

$$
\left\|T x^{(p)}-T x\right\| \leq P\left\|x^{(p)}-x\right\|+C \frac{1-P}{2(C M+L)}\left\|f\left(x_{i}^{(p)}\right)-f\left(x_{i}\right)\right\| \rightarrow 0
$$

and

$$
\lim _{p \rightarrow \infty}\left\|T x^{(p)}-T x\right\|=0
$$

This means that $T$ is continuous. 
Now, we need to compare a measure of noncompactness of any subset $X$ of $B$ and $T(X)$. Let us take a nonempty set $X \subset B$. For any sequences $x, y \in X$, we get

$$
\left|(T x)_{n}-(T y)_{n}\right| \leq P\left|x_{n}-y_{n}\right|+C M \alpha_{n}, \quad n \in \mathbb{N}_{n_{3}} .
$$

Hence, we obtain

$$
\operatorname{diam}(T(X))_{n} \leq k \operatorname{diam} X_{n}+C M \alpha_{n}
$$

This yields

$$
\limsup _{n \rightarrow \infty} \operatorname{diam}(T(X))_{n} \leq k \limsup _{n \rightarrow \infty} \operatorname{diam} X_{n} .
$$

From the above, for any $X \subset B$, we have $\mu(T(X)) \leq k \mu(X)$, where $k=\frac{P+1}{2} \in[0,1)$.

By virtue of Theorem 1, we conclude that $T$ has a fixed point in the set $B$. It means that there exists $x \in B$ such that $x_{n}=(T x)_{n}$. Thus

$$
x_{n}=-p_{n} x_{n-k}+\sum_{j=n}^{\infty} \frac{1}{r_{j}} \sum_{i=j}^{\infty} a_{i} f\left(x_{i}\right), \quad n \in \mathbb{N}_{n_{3}}
$$

for any $n \in \mathbb{N}_{n_{3}}$. To show that there exists a connection between the fixed point $x \in B$ and the existence of a solution of equation (1), we use the operator $\Delta$ for both sides of the following equation:

$$
x_{n}+p_{n} x_{n-k}=\sum_{j=n}^{\infty} \frac{1}{r_{j}} \sum_{i=j}^{\infty} a_{i} f\left(x_{i}\right)
$$

which is obtained from (13). We find that

$$
\Delta\left(x_{n}+p_{n} x_{n-k}\right)=-\frac{1}{r_{n}} \sum_{i=n}^{\infty} a_{i} f\left(x_{i}\right), \quad n \in \mathbb{N}_{n_{3}} .
$$

Using again the operator $\Delta$ for both sides of the above equation, we get equation (1) for $n \in \mathbb{N}_{n_{3}}$. The sequence $x$, which is a fixed point of the mapping $T$, is a bounded sequence which fulfills equation (1) for large $n$. If $n_{3} \leq k$, the proof is ended. If $n_{3}>k$, then we find previous $n_{3}-k+1$ terms of the sequence $x$ by the formula

$$
x_{n-k+l}=\frac{1}{p_{n+l}}\left(-x_{n+l}+\sum_{j=n+l}^{\infty} \frac{1}{r_{j}} \sum_{i=j}^{\infty} a_{i} f\left(x_{i}\right)\right), \quad \text { where } l \in\{0,1,2, \ldots, k-1\},
$$

the results of which follow directly from (1). It means that equation (1) has at least one bounded solution $x: \mathbb{N}_{0} \rightarrow \mathbb{R}$.

This completes the proof.

Example 1 Let us consider the equation

$$
\Delta\left((-1)^{n} \Delta\left(x_{n}+\left(\frac{1}{2}+\frac{1}{2^{n}}\right) x_{n-2}\right)\right)+\frac{3(-1)^{n+1}}{2^{n+2}}\left(x_{n}\right)^{\frac{1}{3}}=0 .
$$


All the assumptions of Theorem 2 are fulfilled. Then there exists a bounded solution $x$ of the above equation. So, the sequence $x_{n}=(-1)^{n}$ is such a solution.

Remark 1 Assume that

$$
p_{n} \equiv p \in(0,1)
$$

and

$$
\sum_{n=0}^{\infty} \sum_{i=n}^{\infty}\left|a_{i}\right|<\infty
$$

in an Emden-Fowler difference equation of the form (2). Then there exists a bounded solution of equation (2).

Proof Here all the assumptions of Theorem 2 are satisfied, e.g., the function $f: \mathbb{R} \rightarrow \mathbb{R}$ given by formula $f(x)=x^{\gamma}$ is a continuous function, and $|f(x)|=\left|x^{\gamma}\right| \leq \gamma|x|+1-\gamma$. So, taking $M=\gamma$ and $L=1-\gamma$, we obtain condition (4). The thesis follows directly from Theorem 2.

Finally, sufficient conditions for the existence of an asymptotically stable solution of equation (1) will be presented. We recall the following definition which can be found in [27].

Definition 2 Let $x$ be a real function defined, bounded, and continuous on $[0, \infty)$. The function $x$ is an asymptotically stable solution of the equation

$$
x=F x .
$$

It means that for any $\varepsilon>0$, there exists $T>0$ such that for every $t \geq T$ and for every other solution $y$ of equation (16), the following inequality holds:

$$
|x(t)-y(t)| \leq \varepsilon
$$

Theorem 3 Assume that there exists a positive constant D such that

$$
|f(x)-f(y)| \leq D|x-y|
$$

for any $x, y \in \mathbb{R}$, and conditions (3)-(6) hold. Then equation (1) has at least one asymptotically stable solution $x: \mathbb{N}_{0} \rightarrow \mathbb{R}$.

Proof From Theorem 2, equation (1) has at least one bounded solution $x: \mathbb{N}_{0} \rightarrow \mathbb{R}$ which can be rewritten in the form

$$
x_{n}=(T x)_{n},
$$

where a mapping $T$ is defined by (12). 
Because of Definition 2, the sequence $x$ is an asymptotically stable solution of the equation $x_{n}=(T x)_{n}$, which means that for any $\varepsilon>0$, there exists $n_{4} \in \mathbb{N}_{0}$ such that for every $n \geq n_{4}$ and for every other solution $y$ of equation (1), the following inequality holds:

$$
\left|x_{n}-y_{n}\right| \leq \varepsilon
$$

From (12), by (7), we have

$$
\left|(T x)_{n}-(T y)_{n}\right| \leq P\left|x_{n-k}-y_{n-k}\right|+\sum_{j=n}^{\infty}\left|\frac{1}{r_{j}}\right| \sum_{i=j}^{\infty}\left|a_{i}\right|\left|f\left(x_{i}\right)-f\left(y_{i}\right)\right|
$$

for $n \geq n_{3}$. The above and (17) yield

$$
\left|(T x)_{n}-(T y)_{n}\right| \leq P\left|x_{n-k}-y_{n-k}\right|+D \sum_{j=n}^{\infty}\left|\frac{1}{r_{j}}\right| \sum_{i=j}^{\infty}\left|a_{i}\right|\left|x_{i}-y_{i}\right|
$$

for $n \geq n_{5}=\max \left\{n_{3}, n_{4}\right\}$. Hence, by (8) and (19), we obtain

$$
\left|(T x)_{n}-(T y)_{n}\right| \leq P\left|x_{n-k}-y_{n-k}\right|+D \sup _{i \geq n}\left|x_{i}-y_{i}\right| \alpha_{n}
$$

for $n \geq n_{5}$. Thus, linking the above inequality and (18), we have

$$
\left|x_{n}-y_{n}\right| \leq P\left|x_{n-k}-y_{n-k}\right|+D \sup _{i \geq n}\left|x_{i}-y_{i}\right| \alpha_{n}
$$

Let us denote

$$
\limsup _{n \rightarrow \infty}\left|x_{n}-y_{n}\right|=l
$$

Because of

$$
\limsup _{n \rightarrow \infty}\left|x_{n}-y_{n}\right|=\limsup _{n \rightarrow \infty}\left|x_{n-k}-y_{n-k}\right|
$$

and (20), we get

$$
l\left(1-P-D \lim _{n \rightarrow \infty} \alpha_{n}\right) \leq 0 .
$$

From the above and (9), we obtain

$$
l(1-P) \leq 0 \quad \text { for enough large } n
$$

Suppose to the contrary that $l>0$. Thus, we obtain a contradiction with the fact that $0<$ $P<1$. Therefore we get $\limsup _{n \rightarrow \infty}\left|x_{n}-y_{n}\right|=0$. This completes the proof.

Remark 2 Under conditions (3)-(6) and (17), any bounded solution of equation (1) is asymptotically stable. 
Proof If boundedness of a solution of equation (1) is assumed, then by virtue of the same arguments as in Theorem 3, the thesis of the above remark is obtained.

Example 2 Let us consider equation (1) with $f(x)=x, a_{n}=\Delta^{2} p_{n}$ and $\sum_{n=0}^{\infty} \sum_{i=n}^{\infty}\left|a_{i}\right|<\infty$. Such an equation has infinitely many solutions of the form $x_{n} \equiv c$, where $c$ is a real constant. All the assumptions of Theorem 3 are fulfilled, then each of such solutions is asymptotically stable.

Theorem 4 Assume that $L=0$ in (4). Under conditions (3)-(6) and (17), if there exists a zero solution of equation (1), then it is asymptotically stable.

Proof If $L=0$, then condition (4) takes the form $|f(x)| \leq M|x|$. This implies that $f(0)=0$. Hence, the sequence $x \equiv 0$ is a bounded solution of equation (1). By Remark 2, the zero solution is asymptotically stable.

Competing interests

The author declares that they have no competing interests.

Acknowledgements

The author would like to thank the reviewers for their helpful comments and valuable suggestions.

Received: 24 August 2012 Accepted: 14 March 2013 Published: 4 April 2013

References

1. Medina, R, Pinto, M: Asymptotic behavior of solutions of second order nonlinear difference equations. Nonlinear Anal. 19, 187-195 (1992)

2. Migda, M: Asymptotic behavior of solutions of nonlinear delay difference equations. Fasc. Math. 31, 57-62 (2001)

3. Migda, J, Migda, M: Asymptotic properties of the solutions of second order difference equation. Arch. Math. 34, 467-476 (1998)

4. Migda, M, Schmeidel, E, Zbąszyniak, M: On the existence of solutions of some second order nonlinear difference equations. Arch. Math. 42, 379-388 (2005)

5. Musielak, R, Popenda, J: The periodic solutions of the second order nonlinear difference equation. Publ. Mat. 32 , 49-56 (1988)

6. Popenda, J, Werbowski, J: On the asymptotic behavior of the solutions of difference equations of second order. Ann. Pol. Math. 22, 135-142 (1980)

7. Schmeidel, E: Asymptotic behaviour of solutions of the second order difference equations. Demonstr. Math. 25, 811-819(1993)

8. Schmeidel, E, Zbąszyniak, Z: An application of Darbo's fixed point theorem in investigation of periodicity of solutions of difference equations. Comput. Math. Appl. (2012). doi:10.1016/j.camwa.2011.12.025

9. Thandapani, E, Arul, R, Graef, JR, Spikes, PW: Asymptotic behavior of solutions of second order difference equations with summable coefficients. Bull. Inst. Math. Acad. Sin. 27, 1-22 (1999)

10. Grace, SR, Lalli, BS: Oscillatory and asymptotic behavior of solutions of nonlinear neutral-type difference equations. J. Aust. Math. Soc. Ser. B 38, 163-171 (1996)

11. Lalli, BS, Grace, SR: Oscillation theorems for second order neutral difference equations. Appl. Math. Comput. 62, 47-60 (1994)

12. Lalli, BS, Zhang, BG: On existence of positive solutions and bounded oscillations for neutral difference equations. J. Math. Anal. Appl. 166, 272-287 (1992)

13. Migda, J, Migda, M: Asymptotic properties of solutions of second-order neutral difference equations. Nonlinear Anal. 63, e789-e799 (2005)

14. Luo, JW, Bainov, DD: Oscillatory and asymptotic behavior of second-order neutral difference equations with maxima. J. Comput. Appl. Math. 131, 333-341 (2001)

15. Luo, J, Yu, Y: Asymptotic behavior of solutions of second order neutral difference equations with 'maxima'. Demonstr. Math. 35, 83-89 (2001)

16. Baštinec, J, Berezansky, L, Diblík, J, Šmarda, Z: A final result on the oscillation of solutions of the linear discrete delayed equation $\Delta x(n)=-p(n) x(n-k)$ with a positive coefficient. Abstr. Appl. Anal. 2011, Article ID 586328 (2011)

17. Baštinec, J, Diblík, J, Šmarda, Z: Existence of positive solutions of discrete linear equations with a single delay. J. Differ. Equ. Appl. 16, 1047-1056 (2010)

18. Berezansky, L, Diblík, J, Růžičková, M, Šutá, Z: Asymptotic convergence of the solutions of a discrete equation with two delays in the critical case. Abstr. Appl. Anal. 2011, Article ID 709427 (2011)

19. Diblík, J, Hlavičková, I: Asymptotic behavior of solutions of delayed difference equations. Abstr. Appl. Anal. 2011 Article ID 671967 (2011)

20. Diblík, J, Růžičková, M, Šutá, Z: Asymptotic convergence of the solutions of a discrete equation with several delays. Appl. Math. Comput. 218, 5391-5401 (2012) 
21. Agarwal, RP: Difference Equations and Inequalities. Theory, Methods, and Applications, 2nd edn. Monographs and Textbooks in Pure and Applied Mathematics, vol. 228. Dekker, New York (2000)

22. Elaydi, SN: An Introduction to Difference Equations, 3rd edn. Undergraduate Texts in Mathematics. Springer, New York (2005)

23. Kocić, VL, Ladas, G: Global Behavior of Nonlinear Difference Equations of Higher Order with Applications. Mathematics and Its Applications, vol. 256. Kluwer Academic, Dordrecht (1993)

24. Kelley, WG, Peterson, AC: Difference Equations: An Introduction with Applications. Academic Press, San Diego (2001)

25. Akhmerov, RR, Kamenskij, MI, Potapov, AS, Rodkina, AS, Sadovskij, BN: Measures of Noncompactness and Condensing Operators. Operator Theory: Advances and Applications, vol. 55. Birkhäuser, Basel (1992). Translated from the Russian by A. lacob

26. Banaś, J, Goebel, K: Measures of Noncompactness in Banach Spaces. Lecture Notes in Pure and Applied Mathematics, vol. 60. Dekker, New York (1980)

27. Banaś, J, Rzepka, B: An application of measure of noncompactness in study of asymptotic stability. Appl. Math. Lett. $16,1-6(2003)$

doi:10.1186/1687-1847-2013-91

Cite this article as: Schmeidel: An application of measures of noncompactness in the investigation of boundedness of solutions of second-order neutral difference equations. Advances in Difference Equations 2013 2013:91.

\section{Submit your manuscript to a SpringerOpen ${ }^{\ominus}$ journal and benefit from:}

- Convenient online submission

Rigorous peer review

- Immediate publication on acceptance

Open access: articles freely available online

- High visibility within the field

- Retaining the copyright to your article 